\title{
What Makes a Leader? An Investigation into the Relationship between Leader Emergence and Effectiveness
}

\author{
Luke Treglown 1,2*, Stephen Cuppello1, Jayson Darby', Sonya Bendriem ${ }^{3}$, Scott Mackintosh ${ }^{3}$, \\ Merle Ballaigues, ${ }^{4}$ Ian MacRaes, Adrian Furnham6
}

${ }^{1}$ Thomas International, Marlow, United Kingdom

${ }^{2}$ University College London, London, United Kingdom

${ }^{3}$ Aptology, San Francisco, California, United States of America

${ }^{4}$ Thomas International, Oakville, Canada

${ }^{5}$ High Potential Psychology Ltd., London, United Kingdom

${ }^{6}$ Norwegian Business School (BI), Nydalsveien, Oslo, Norway

Email: ^LukeT@Thomas.co.uk

How to cite this paper: Treglown, L., Cuppello, S., Darby, J., Bendriem, S., Mackintosh, S., Ballaigues, M., MacRae, I., \& Furnham, A. (2020). What Makes a Leader? An Investigation into the Relationship between Leader Emergence and Effectiveness. Psychology, 11, 1381-1400.

https://doi.org/10.4236/psych.2020.119089

Received: August 21, 2020

Accepted: September 26, 2020

Published: September 29, 2020

Copyright $\odot 2020$ by author(s) and Scientific Research Publishing Inc. This work is licensed under the Creative Commons Attribution International License (CC BY 4.0).

http://creativecommons.org/licenses/by/4.0/

\begin{abstract}
Are the traits that predict leadership emergence the same that predict leadership effectiveness? How do leader attributes play either a direct or dynamic role in predicting organisational outcomes? This paper presents an investigation into the personality-performance relationship to address these questions. 936 general population and 198 senior leadership participants took the High Potential Trait Indicator (HPTI). The first part examined how levels of personality traits differentiated leaders from a general population. The second examined the relationship between leader personality, competencies and organizational success to assess whether the traits of leader emergence are the same as effectiveness. Additionally, this section simultaneously examined the role of leader traits and attributes play in predicting organizational performance. The results indicated that all six HPTI traits were associated with leader emergence. However, only three-Adjustment, Risk Approach, and Ambiguity Acceptance-were also positively predictive of leadership effectiveness. Curiosity showed mixed benefits for leaders, whilst Conscientiousness and Competitiveness did not differentiative leader effectiveness. Additionally, leader attributes were found not to predict performance. This paper offers novel insight into the important role of personality in distinguishing leader emergence as well as leader effectiveness. Implications are discussed in relation to models of leadership and potential, as well as for practice include identifying high potential talent and diversity in psychometric testing.
\end{abstract}




\section{Keywords}

Leadership Personality, Leaders Performance, Leadership Competencies, Organizational Performance

\section{Introduction}

There is a growing interest in Organisational Psychology to understand both the personality traits that predict leadership emergence, as well as how traits of leaders impact the success of their organisation (Colbert et al., 2014; Waldman \& Yammarino, 1999). Academics have conceptualised personality in two ways: how a person thinks about themselves, and how others think about that person (Hogan \& Kaiser, 2005). It describes the "fundamental, consistent aspects of how a person thinks and reacts emotionally, and how those reactions influence behaviour" (MacRae \& Furnham, 2014). Models of leadership, including Behrendt et al.'s (2017) integrative model of leadership behaviour, allude to personality as an important mechanism of effective leadership as a function of task-orientation (to accomplish objectives) and relation-orientation (to be able to influence followers to invest efforts in task-orientated objectives).

Personality researchers argued that personality traits contribute to leader emergence in two ways: firstly, traits are argued to contribute to the speed at which someone is promoted to leadership because these traits contribute to an employee's work ethic, dependability, and reliability (Furnham et al., 2013); secondly, personality has been shown to influence leader emergence as a function of political or networking skills (Furnham et al., 2013). Teodorescu, Furnham, and Macrae (2017) investigated associations between personality traits and leader emergence, finding personality to be predictive of objective measures of leadership emergence (e.g. promotion rates), with Conscientiousness being the strongest predictor. Personality has been shown to reliably explain variance in leadership emergence (Ensari et al., 2011), with recent studies showing that traits such as Conscientiousness, Extraversion, Openness, and Agreeableness being predictive of emergence (Judge et al., 2002).

Whilst it is useful to understand the role of personality in leadership emergence, studies have also looked at the scale of the impact that leaders have on an organisation. One study found that $14 \%$ of an organisation's performance is attributable to their CEO (Joyce et al., 2003). If senior leaders account for a significant amount of organisational performance, and personality predicts which leaders rise to top, it suggests that CEO personality should have a significant impact on organisational performance as a function of the CEOs approach to leadership style and decision-making style. However, this is not always the case. There is an interesting discord between the traits associated with leadership emergence and leadership effectiveness (e.g. Grijalva et al., 2015). For instance, leader levels of Conscientiousness (i.e. tendencies to be orderly, forward planning, thorough, and achievement orientated; Goldberg, 1992) have been argued 
to have both positive and negative implications for leader effectiveness (Harris et al., 2019; Hogan \& Hogan, 2001; Judge et al., 2009). Judge et al. (2002) found certain traits to be predictive of emergence but not of effectiveness. Scholars have therefore criticised the current literature's focus on leadership personality as being too narrow, lacking coherence, and instead promoting a fragmented understanding of leadership individual difference (e.g. Zaccaro et al., 2018).

As such, there have been calls for research to examine and address how additional leadership attributes, beyond leader traits, play a direct or dynamic role in predicting proximal or distal organisational outcomes (e.g. Judge et al., 2002; Harris et al., 2019; Zaccaro et al., 2018; Ng et al., 2008; Tuncdogan et al., 2017). One such approach has been to shift from predictor-centric analysis (i.e. "what does trait $X$ predict in the work context?") to one that is more criterion-centric (i.e. “how do we predict outcome Y?") (Bartram, 2005). As such, the role of leadership competencies that categorise specific behaviours, styles, and approaches have been used as both criterion and predictor variables in leadership research (e.g. Barrett \& Depinet, 1991). However, there have been critics of the use of competency metrics as predictor variables, primarily because it is argued that it is hard to distinguish competencies from performance when frameworks are typically characterised in relation to performance outcomes (e.g. Markus et al., 2005). As such, there is a lack of consensus in the role of competencies as predictors of objective performance. Few studies have, however, looked at the combined role of personality and competencies in predictive objective performance; for instance, leadership competencies could play an interactive role in the relationship between personality and performance, uncovering how specific behavioural manifestations of traits contribute to performance.

This paper presents an opportunity to examine several theoretical questions in the leadership literature. Firstly, to what extent does personality predict both leadership emergence and effectiveness? As previous research has demonstrated that the personality-emergence and personality-performance relationship differs on job context (e.g. business versus military leadership), this study will examine how personality traits differ in leader compared to a general working population sample. This will provide insight into whether there are traits that universally facilitate leader emergence. Secondly, to what extent does personality predict leadership effectiveness? Additionally, are these traits similar to those that predict leader emergence? This study will examine the role of leader personality in relation to organisational outcomes, with reference to how leadership competencies interactive with traits to influence leader effectiveness. However, due to the lack of literature on the combined effect of personality and leadership competencies on organisational performance, this part of the study will be exploratory in nature.

\section{Method}

\subsection{Participants}

A general population sample was created to understand the localized trait distributions for the six HPTI traits. All volunteered to take part in an organisa- 
tional research programme on the validation of personality tests. The sample consisted on 936 participants, 501 (54\%) of which were female and with a mean age of 37.95 years $(S D=13.37$ ). The most frequent level of education in the general population sample was qualification at Bachelor level $(n=236,25 \%)$, with the next more frequent being qualification at high school level $(\mathrm{n}=182,19 \%)$ and college/non-university certificate $(\mathrm{n}=157,17 \%)$. Most participants were in some form of full-time employment $(n=705,75 \%)$, with $10 \%$ being in part-time employment $(n=96), 6 \%$ were students $(n=60)$, and $2 \%$ unemployed $(n=17)$. Employed participants came from 28 different industries, with the most frequent being Education ( $\mathrm{n}=100,11 \%)$, Retail $(\mathrm{n}=96,10 \%)$, and Health $(\mathrm{n}=88,9 \%)$.

Data on 198 executive leaders from Canada and the USA was gathered to establish a separate leadership sample. The senior leadership sample comprised of 71 female (35.8\%) and 127 male (64.2\%) leaders, with a mean age of 48.6 years $(\mathrm{SD}=8.26)$. Leaders' organizational tenure ranged from less than one year $(\mathrm{n}=$ $10,5 \%)$ to more than 20 years $(\mathrm{n}=28,14 \%)$, whilst most leaders' tenure in their current role ranged from 6 months to 6 years $(n=131,66 \%)$. The most common level of education within the leadership sample was a qualification at Masters level $(\mathrm{n}=70,35 \%)$, with qualifications at Bachelors $(\mathrm{n}=54,27 \%)$, Honors $(\mathrm{n}=$ $37,19 \%)$, and college level $(\mathrm{n}=18,9 \%)$ being the next most common. Finally, leaders were selected from 22 different industries, with Manufacturing $(\mathrm{n}=31$, $16 \%)$, Information Technology $(\mathrm{n}=17,9 \%)$ and Financial Institutions $(\mathrm{n}=16$, $8 \%)$ being the most common. The leaders that participated in the study completed the HPTI and an additional questionnaire that gathered information on organizational performance and leadership competencies.

\subsection{Materials}

High Potential Trait Indicator (HPTI; MacRae \& Furnham, 2014; MacRae, 2012)-MacRae and Furnham created a taxonomy of personality at work, the High Potential Traits Inventory (HPTI), based on Silzer and Church's (2009a, 2009b) theoretical framework of potential. The HPTI was designed to provide an accurate, valid and clear measure of personality at work and can be used to investigate which personality traits in the workplace might predict career success and thus predict high potential. Originally composed of ten factors and characteristics related to success and leadership capability, the traits were recombined into six common factors (MacRae, 2012): Conscientiousness, Adjustment, Curiosity, Ambiguity Acceptance, Risk Approach, and Competitiveness. Descriptions of the traits and how they relate to the Big Five taxonomy of personality can be found in Table 1.

HPTI represents a 78-item measure of personality traits directly relevant to workplace behaviours, thoughts and perceptions. Teodorescu et al. (2017) used the HPTI to investigate associations between personality traits and measures of career success, in a sample of 383 employed individuals. Previous research has shown the HPTI to have good internal reliability, with alphas ranging from $\alpha=.72$ (Risk Approach) to $\alpha=.80$ (Curiosity; MacRae \& Furnham, 2014; MacRae, 2012). 
Table 1. HPTI trait descriptions.

\begin{tabular}{cl}
\hline HPTI Trait & \multicolumn{1}{c}{ Description } \\
\hline Conscientiousness & Focused on goals and self-motivation. \\
Adjustment & Fewer feelings of stress and calm under pressure. \\
Curiosity & Enjoy novelty, learning, and variety. \\
Risk Approach & $\begin{array}{l}\text { Proactive in confronting challenging situations and } \\
\text { difficult conversations. } \\
\text { Ambiguity Acceptance }\end{array}$ \\
Competitiveness & Thrive on uncertainty and complexity. \\
& Enjoys positions of power, influence, and recognition.
\end{tabular}

Leadership Competencies-A literature review was conducted on categorisations and taxonomies of leadership competencies, focusing on personality traits, competencies, and behavioural studies. From this research, an initial list of 79 traits were highlighted as being important for leadership effectiveness. These were thematically clustered in order to create fifteen distinct leadership competencies (shown in Table 2). Leaders were asked to select their top five personal leadership strengths, which were scored from 5 (top strength picked) to 1 (fifth strength picked). Unselected competencies were scored as 0 . In the analysis, these ratings gauged both whether the leader considered the competency to be a strength, as well as the extent to which they saw this as a strength.

Organisational Performance Metrics-As the leadership sample for this study wanted to remain anonymous, data on self-report measures of performance were gathered to assess organisational performance metrics. Performance was defined using the Dynamic Multi-Dimensional Performance Model (Maltz et al., 2003), which looked not only at financial outcomes, but also at measures the market/customer, process, people development, and future aspects of a business. The following aspects were reported on: annual revenue, attrition (\%), revenue growth, EBITDA growth, employee engagement, promotions or roles filled by internal roles (\%), performance targets met (\%), time to market, innovation, total sales growth, net profit margin, customer satisfaction, customer retention, retention of top talent, and overall performance (previous eight rated on a comparative likert scale from 1 [significantly worse than other competitors in your industry] and 5 [significantly better than other competitors in your industry]).

\section{Results}

ANOVAs were run to test for any potential differences in Canadian and American personality for the general population and leadership samples. No significant differences were seen between the two countries on two of the six traits (Conscientiousness and Competitiveness). For three of the significant differences, the effect sizes did not reach the cut off for small (Adjustment, $\eta^{2}=.001$; Risk Approach, $\eta^{2}=.009 ;$ Ambiguity Acceptance, $\left.\eta^{2}=.005\right)$ and the final difference was at the lower border of small (Curiosity, $\eta^{2}=.014$ ). As no medium or large differences were seen between the two groups, the sample was combined. The results can be found in Table 3 . 
Table 2. Descriptions of the 15 leadership competencies derived from literature review.

\begin{tabular}{|c|c|c|}
\hline Competency & Description & $\begin{array}{l}\text { Competency Characteristics } \\
\text { from the Literature }\end{array}$ \\
\hline $\begin{array}{l}\text { Integrative } \\
\text { thinker }\end{array}$ & $\begin{array}{l}\text { Absorbs and integrates complex } \\
\text { and contrasting information from } \\
\text { diverse sources as a preferred } \\
\text { problem-solving strategy. }\end{array}$ & $\begin{array}{l}\text { Integrative thinking, absorptive capacity, } \\
\text { thinking divergently about new ways of } \\
\text { doing things, handling eve-increasing } \\
\text { cognitive complexity, quick learner. }\end{array}$ \\
\hline $\begin{array}{l}\text { Strategic } \\
\text { visionary }\end{array}$ & $\begin{array}{l}\text { Creates a sense of purpose for } \\
\text { the future; vividly describes their } \\
\text { vision and provides direction } \\
\text { for how to get there. }\end{array}$ & $\begin{array}{l}\text { Future-orientation; display excellent strategic } \\
\text { vision; vividly describes their vision of the } \\
\text { future and how to get there, visionary, provide } \\
\text { vision and direction; growth orientation; } \\
\text { conceptualising possibilities in a virtual world; } \\
\text { strategic perspective; strategic planning. }\end{array}$ \\
\hline $\begin{array}{l}\text { Adaptable } \\
\text { \& flexible }\end{array}$ & $\begin{array}{l}\text { Resilient and adaptable to change; } \\
\text { thrives in a complex and } \\
\text { uncertain environment. }\end{array}$ & $\begin{array}{l}\text { Behavioural complexity, capacity to change, } \\
\text { has the flexibility to change opinions, } \\
\text { adapting to constantly, shifting power and } \\
\text { influence, tolerating environment of risk and } \\
\text { ambiguity, showing resilience in the face of } \\
\text { constant change, change management }\end{array}$ \\
\hline Innovator & $\begin{array}{l}\text { Confidently drives change; } \\
\text { is open to new ideas and } \\
\text { approaches; fosters a creative } \\
\text { and participative environment. }\end{array}$ & $\begin{array}{l}\text { Is open to new ideas and approaches show } \\
\text { openness to new ideas and foster } \\
\text { organisational learning, inventing } \\
\text { (enabling and empowering others to create } \\
\text { new processing/ ideas to help move org } \\
\text { forward) drive change and innovation; } \\
\text { being brave in challenging how things are } \\
\text { being done, having the confidence to take } \\
\text { the lead in driving change }\end{array}$ \\
\hline $\begin{array}{l}\text { Empowers } \\
\text { others }\end{array}$ & $\begin{array}{l}\text { Fosters a learning culture; } \\
\text { motivates others to challenge } \\
\text { themselves and take ownership; } \\
\text { provides safety for trial and error. }\end{array}$ & $\begin{array}{l}\text { Empower others to self-organise (allow others } \\
\text { to make mistakes and empower them to make } \\
\text { decisions); provides goals and objectives with } \\
\text { loose guidelines/ direction; provides safety for } \\
\text { trial and error, sets growth goals/ motivate } \\
\text { others to stretch themselves, participative, } \\
\text { empower others in organization; } \\
\text { transformational leadership; investing huge } \\
\text { amounts of energy into getting things right, } \\
\text { try, fail, try again; participative management }\end{array}$ \\
\hline Talent-builder & $\begin{array}{l}\text { Priotizes people and their } \\
\text { development; capitalizes on } \\
\text { individual talent and drives a } \\
\text { high performance culture. }\end{array}$ & $\begin{array}{l}\text { Helps me grow into a next-generation leader, } \\
\text { exploits and maintains core competencies } \\
\text { (resources and capabilities)/ knowledge } \\
\text { management, developed and mobilization of } \\
\text { human capital(knowledge and skills;) } \\
\text { build talent for competitive advantage, } \\
\text { employee development }\end{array}$ \\
\hline $\begin{array}{l}\text { Leads } \\
\text { with integrity }\end{array}$ & $\begin{array}{l}\text { Values-driven ambassador, } \\
\text { uncompromising in their personal } \\
\text { moral and ethical standards. }\end{array}$ & $\begin{array}{l}\text { Demonstrates strong ethics and provides a } \\
\text { sense of safety, has high ethical and moral } \\
\text { standards, integrity, self sacrificial }\end{array}$ \\
\hline $\begin{array}{l}\text { Fosters } \\
\text { a culture } \\
\text { of unity } \\
\text { and belonging }\end{array}$ & $\begin{array}{l}\text { Effective at developing team } \\
\text { cohesion, a sense of connection } \\
\text { and trust; successful at } \\
\text { encouraging individuals to work } \\
\text { together towards a common goal. }\end{array}$ & $\begin{array}{l}\text { Nurtures growth; } \\
\text { foster a sense of connection and belonging }\end{array}$ \\
\hline
\end{tabular}




\section{Continued}

\begin{tabular}{|c|c|c|}
\hline Collaborator & $\begin{array}{l}\text { Identifies and leverages the skills } \\
\text { of others; rapidly creates synergy } \\
\text { in complex networks through } \\
\text { working in partnerships. }\end{array}$ & $\begin{array}{l}\text { Creates a feeling of succeeding and failing } \\
\text { together, team integrator, collaborative team } \\
\text { orientation; create synergies through working } \\
\text { in partnership collaborating with ease across } \\
\text { many different teams, valuing the contribution } \\
\text { of new work partners and different interest } \\
\text { groups, building collaborative relationships }\end{array}$ \\
\hline $\begin{array}{l}\text { Effective } \\
\text { communicator }\end{array}$ & $\begin{array}{l}\text { Sets clear expectations; } \\
\text { communicates openly, honestly } \\
\text { and frequently; knows how to } \\
\text { modify for diverse audiences. }\end{array}$ & $\begin{array}{l}\text { Communicates clear expectations, } \\
\text { communicates often and openly, } \\
\text { create a climate of reciprocal trust, } \\
\text { create warm collaborative relationships }\end{array}$ \\
\hline $\begin{array}{c}\text { Charismatic \& } \\
\text { inspirational }\end{array}$ & $\begin{array}{l}\text { Projects optimism and energy; } \\
\text { persuasive and charismatic } \\
\text { even in times of crisis; } \\
\text { inspires commitment. }\end{array}$ & $\begin{array}{l}\text { Inspiring and motivational; project optimism } \\
\text { and energy, charismatic and persuasive } \\
\text { (even in times of crisis); inspires and } \\
\text { motivates through action; inspirational } \\
\text { persuade and influence stakeholders, inspire } \\
\text { people to follow them; inspiring commitment }\end{array}$ \\
\hline $\begin{array}{l}\text { Social and } \\
\text { emotional } \\
\text { intelligence }\end{array}$ & $\begin{array}{l}\text { Exhibits high levels of } \\
\text { self-awareness; recognises and } \\
\text { understands their emotions } \\
\text { as well as those of others; } \\
\text { harnesses this insight to have } \\
\text { effective interactions and drive } \\
\text { performance with a diverse } \\
\text { range of people. }\end{array}$ & $\begin{array}{l}\text { Managerial wisdom social intelligence, } \\
\text { emotional intelligence, understands } \\
\text { others and owns emotions }\end{array}$ \\
\hline $\begin{array}{l}\text { Customer } \\
\text { acumen }\end{array}$ & $\begin{array}{l}\text { Keen and quick to gain insight } \\
\text { on customers and market; } \\
\text { applies the insight for } \\
\text { competitive advantage. }\end{array}$ & $\begin{array}{l}\text { Seek to get inside customers minds, } \\
\text { understand their needs and wants, } \\
\text { show commercial acumen and } \\
\text { business judgment }\end{array}$ \\
\hline $\begin{array}{c}\text { Decisive \& } \\
\text { accountable }\end{array}$ & $\begin{array}{l}\text { Executes and achieves results } \\
\text { through quick and effective } \\
\text { decision making even with } \\
\text { limited information; } \\
\text { follows through and takes } \\
\text { ownership of outcomes. }\end{array}$ & $\begin{array}{l}\text { Creates sense of purpose effective } \\
\text { organizational culture; culture of } \\
\text { knowledge sharing }\end{array}$ \\
\hline $\begin{array}{l}\text { Proactive } \\
\text { conflict } \\
\text { manager }\end{array}$ & $\begin{array}{l}\text { Comfortable with handling } \\
\text { difficult situations; } \\
\text { tackles conflict head-on and uses } \\
\text { it as an opportunity to improve. }\end{array}$ & $\begin{array}{l}\text { Decisive execute and achieve results } \\
\text { through their people making decisions } \\
\text { quickly without all of the information; } \\
\text { taking initiative }\end{array}$ \\
\hline
\end{tabular}

Additional analysis was conducted to check for gender differences in personality. The sample was $64 \%$ male and $36 \%$ female. Whilst the gender ratio is skewed, it is more balanced than what is seen currently in North America: e.g. in 2017, 29\% of senior management positions were held by women in Canada (Canadian Labor Statistic, 2017). For the leadership sample, tests found no significant differences between gender for any of the HPTI traits. For the population sample, only two significant differences were seen, with men scoring higher than women on Adjustment, Risk Approach and Competitiveness, but the effect size of these differences were negligible or small $\left(\eta^{2}=.009, \eta^{2}=.021\right.$ and .019 respectively). The results can be found in Table 4. 
Table 3. Means, standard deviation, and results of ANOVA for HPTI by country.

\begin{tabular}{ccccc}
\hline & $\begin{array}{c}\text { Total } \\
(\mathrm{n}=1134)\end{array}$ & $\begin{array}{c}\text { Canada } \\
(\mathrm{n}=725)\end{array}$ & $\begin{array}{c}\text { USA } \\
(\mathrm{n}=409)\end{array}$ & \multirow{2}{*}{ F-Score $(\eta)$} \\
\cline { 2 - 4 } & Mean (SD) & Mean (SD) & Mean (SD) & \\
\cline { 2 - 4 } Conscientiousness & $57.5(15.5)$ & $58.1(15.0)$ & $56.5(16.3)$ & $2.84(.003)$ \\
Adjustment & $58.8(18.0)$ & $60.1(17.7)$ & $56.5(18.2)$ & \multirow{2}{*}{$9.96^{* *}(.001)$} \\
Curiosity & $55.3(14.3)$ & $56.6(14.0)$ & $53.0(14.4)$ & \multirow{2}{*}{$16.6^{* * *}(.014)$} \\
Risk Approach & $54.9(14.2)$ & $55.9(13.8)$ & $53.2(14.6)$ & $9.92^{* *}(.009)$ \\
Ambiguity Acceptance & $51.7(12.5)$ & $52.2(12.7)$ & $50.6(12.0)$ & $5.18^{\star}(.005)$ \\
Competitiveness & $50.3(14.1)$ & $50.2(14.0)$ & $50.5(14.2)$ & $0.134(.000)$ \\
\hline
\end{tabular}

Note: ${ }^{* *}=p<.001 ;{ }^{* *}=p<.01 ;^{*}=p<.05$.

Table 4. Means, standard deviation, and results of ANOVA for HPTI by gender.

\begin{tabular}{ccccc}
\hline & $\begin{array}{c}\text { Total } \\
(\mathrm{n}=1134)\end{array}$ & $\begin{array}{c}\text { Male } \\
(\mathrm{n}=562)\end{array}$ & $\begin{array}{c}\text { Female } \\
(\mathrm{n}=572)\end{array}$ & \multirow{2}{*}{ F-Score $(\eta)$} \\
\cline { 2 - 4 } & Mean (SD) & Mean (SD) & Mean (SD) & \\
\hline Conscientiousness & $57.5(15.5)$ & $58.1(16.0)$ & $56.9(15.0)$ & $1.67(.001)$ \\
Adjustment & $58.8(18.0)$ & $60.5(18.6)$ & $57.0(17.2)$ & $10.6^{* *}(.009)$ \\
Curiosity & $55.3(14.3)$ & $55.5(14.6)$ & $55.0(13.9)$ & $0.347(.000)$ \\
Risk Approach & $54.9(14.2)$ & $57.0(14.1)$ & $52.9(14.0)$ & $24.2^{* * *}(.021)$ \\
Ambiguity Acceptance & $51.7(12.5)$ & $52.6(12.7)$ & $50.8(12.2)$ & $5.99(.005)$ \\
Competitiveness & $50.3(14.1)$ & $52.3(13.9)$ & $48.4(14.0)$ & $22.3^{* * *}(.019)$ \\
\hline
\end{tabular}

Note: ${ }^{* *}=p<.001 ;^{* *}=p<.01 ;^{*}=p<.001$.

ANOVAs were run to assess whether leader personality differs significantly from the general population. Results can be found in Table 5. The results indicated that leaders had significantly higher means for all six HPTI traits. Only one difference was small in effect size (Competitiveness; $\eta^{2}=.030$ ), one was medium (Curiosity, $\eta^{2}=.067$ ), and the rest had large effect sizes.

Structural equation modelling was used to analyse the relationship between leaders' HPTI traits, self-rated leadership strengths, and organisational outcomes. The results of this can be seen in Figure 1. The chi-squared statistic was non-significant $\left(\chi^{2}(81)=84.9 ; p=.361\right)$, with other fit metrics indicating an excellent model of the data: $\chi^{2} / d f=1.05$; CFI $=.99$; TLI $=.97$; RMSEA $=.019$. The direct impact of HPTI on organisational performance were: Curiosity was positively predictive of higher Sales Revenue Growth but negatively predictive of Individual Performance Targets; Ambiguity Acceptance was positively predictive of higher annual Organisational Revenue; Risk Approach was positively predic- 
tive of achieving a greater proportion of Performance Targets; and Adjustment was positively predictive of Performance Targets, Net Profit Margin Growth, Innovation, higher rates of Talent Retention, higher rates of Customer Satisfaction, and higher perceived Organisational Performance. Leaders that had Strategic Vision and Effective Communication as leadership strengths were seen to have higher rates of positions filled by internal applicants (indicating a focus on internal development and promotion). Finally, HPTI was also predictive of what leadership competencies leaders viewed as strengths: Competitiveness was negatively predictive of being a Collaborator, Curiosity was positively predictive of Empowering Others and Innovation but negatively predictive of Leading with Integrity, and Adjustment was negatively predictive of being a Proactive Conflict Manager.

Table 5. Means, standard deviation, and results of ANOVA for HPTI by leadership.

\begin{tabular}{ccccc}
\hline & $\begin{array}{c}\text { Total } \\
(\mathrm{n}=1134)\end{array}$ & $\begin{array}{c}\text { Leader Sample } \\
(\mathrm{n}=198)\end{array}$ & $\begin{array}{c}\text { Population Sample } \\
(\mathrm{n}=936)\end{array}$ & \multirow{2}{*}{ F-Score $(\eta)$} \\
\cline { 2 - 4 } & Mean $(\mathrm{SD})$ & Mean (SD) & Mean (SD) & \\
\hline Conscientiousness & $57.5(15.5)$ & $70.7(14.9)$ & $54.7(14.1)$ & $204.9^{* * *}(.153)$ \\
Adjustment & $58.8(18.0)$ & $81.4(9.18)$ & $54.0(15.6)$ & $567.1^{* * *}(.334)$ \\
Curiosity & $55.3(14.3)$ & $63.3(14.0)$ & $53.6(13.7)$ & $81.7^{* * *}(.067)$ \\
Risk Approach & $54.9(14.2)$ & $68.1(11.7)$ & $52.2(13.1)$ & $251.5^{* * *}(.182)$ \\
Ambiguity Acceptance & $51.7(12.5)$ & $65.1(9.84)$ & $48.8(11.0)$ & $371.7^{* * *}(.247)$ \\
Competitiveness & $50.3(14.1)$ & $55.6(12.4)$ & $49.2(14.1)$ & $35.1^{* * *}(.030)$ \\
\hline
\end{tabular}

Note: ${ }^{* *}=p<.001 ;^{* *}=p<.01{ }^{*}=p<.05$.

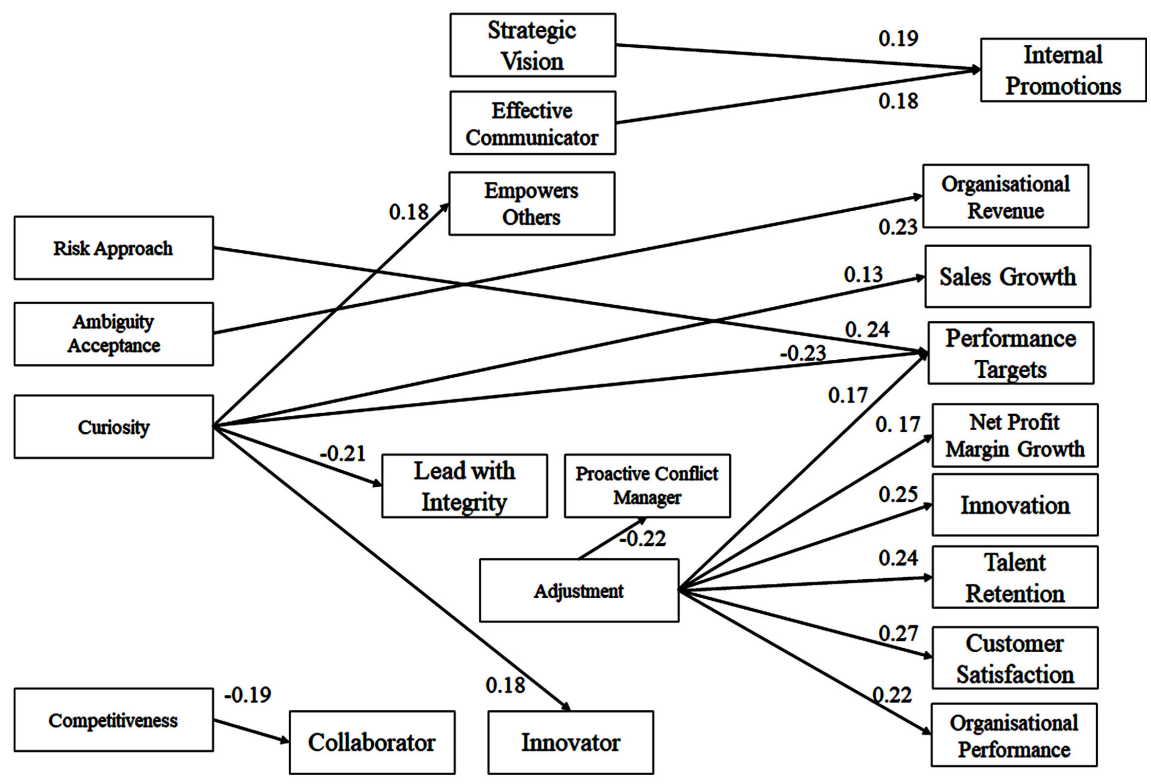

Figure 1. Results from the SEM. 


\section{Discussion}

This paper examined the role of personality in leadership emergence and effectiveness simultaneously, with the aim to understand how specific traits distinguish those employees who become leaders compared to what drives success in those roles. Additionally, this study aimed to address calls by scholars to extent leader trait research by exploring the interactive role of leader attributes on organisational outcomes.

\section{Traits of Leader Emergence and Effectiveness}

The first aim of this study was to examine the role of personality in both leadership emergence and effectiveness. Meta-analyses have indicated that certain traits might play an important role for each process (Judge et al., 2002). However, there is little research looking at the emergence and effectiveness simultaneously to address whether there is uniformity between the traits of emergence and effectiveness. If there is continuity in the traits associated with both processes, it indicates that there are potentially universal leadership benefits to specific traits. If there is discord, however, what does this reveal about how we should theorize the personality-leadership relationship for emergence and effectiveness?

Looking firstly at emergence, results explored variability in leader personality from the general population. Leaders were found to have higher levels of all six HPTI traits compared to the general population. The largest differentiator between leaders and non-leaders were Adjustment and Conscientiousness (as determined by effect size), which supports previous research in this space, finding that lower neuroticism and higher conscientiousness are two of the biggest predictors of leadership (Judge et al., 2002). Several meta-analyses have shown that emotional stability is related to leadership, with Judge et al. (2002) finding it to correlate with leadership emergence and Bono and Judge (2004) showing it to be a consistent correlate of transformational leadership. Additionally, large differences were seen in Ambiguity Acceptance and Risk Approach. Previous research has argued that personality represents the most important, distinguishing characteristic from leaders and non-leaders (Hogan \& Judge, 2013). Models such as Silzer and Church's (2009a, 2009b) model of potential and the integrative model of leadership behavior (Behrendt et al., 2017) position stable traits, such as personality, as the means by which individuals can be successful via achievementand relationship-orientated. Ensari et al.'s (2011) meta-analysis argued for the utility of the Big Five model as a means for identifying leadership emergence. This adds to the literature by broadening our understanding of what characteristics and traits contribute to emergence. Previous research has found that being assertive (i.e. Risk Approach) and comfortable operating under uncertainty (i.e. Ambiguity Acceptance) are also important to leadership success (e.g. Pollanen et al., 2017; Slawinski et al., 2017), but this study is the first to show the extent to which leaders need to have these skills to differentiate themselves from other employees. 
This study continues the trend of leader trait research, demonstrating that personality acts as a foundational dimension in identifying those who go on to leadership positions. As "bright" taxonomies of personality outline traits that relate to the interpersonal behaviours we exhibit when we are being purposeful, positive, and at our best (Hogan et al., 1994), it suggests that leads have more of these traits that average population. However, as mentioned previously, studies have shown a disconnection between some traits that predict leadership emergence compared to the traits that predict success in this role. The second aim of this study was to examine the role of personality in leader effectiveness.

Exploratory analysis through SEM revealed that certain traits-namely $A d$ justment, Risk Approach, and Ambiguity Acceptance-had positive impacts on leadership effectiveness. Leaders that were willing to proactively confront difficult situations and decisions at work (i.e. Risk Approach) had achieved a higher proportion of organisational performance targets. The ability to be decisive (a related construct to Risk Approach) and implement strategic decisions (in place of strategic planning) has been shown to increase organisational performance (Pollanen et al., 2017).

Being a more secure and relaxed, even under pressure (i.e. high Adjustment), was associated with a range of positive organisational outcomes, including higher performance targets, net profit margin growth, innovation, higher rates of talent retention, higher rates of customer satisfaction, and higher perceived organisational performance. Neuroticism (i.e. low Adjustment) has been shown to consistently negatively correlate with leadership potential and performance (e.g. Judge et al., 2002; Barrick et al., 2001). Theories such as the Job Demand-Resource model (JDR; Bakker \& Demerouti, 2014) argue that successful leaders are better able to allocate psychological resources to deal with pressure and stress, meaning they continue to have the needed resources for completing their role successfully (Dixon et al., 2017).

There has been little research on the influence of tolerance of ambiguity or uncertainty and performance, both at an employee and organisational level. However, research has found that uncertainty avoidance and short-termism in organisations is predictive of inaction on climate change (Slawinksi et al., 2017). If inaction is a common symptom of leadership styles that are characterised by uncertainty avoidance, it can be expected that leaders will be inactive in other areas of the business. Building on this, research has suggested that organisations in high uncertainty avoidance cultures are characterised by lower corporate risk-taking (Li et al., 2013), supporting the notion of inaction or unwillingness for an organisation to venture into new territories due to uncertainty of success (i.e. a measure of corporate risk-taking was R\&D investments, which have commonly been regarded as an indicator of risk due to the low likelihood of success for most $\mathrm{R} \& \mathrm{D}$ projects as well as distant and uncertain return on investments (Bargeron et al., 2010). As a consequence, this inaction or failure to innovate could stagnate business operations and lead to lower overall organisational revenue. Future research should look to further explore whether inaction 
plays a mediating role in explaining the relationship between Ambiguity Acceptance and organisational revenue.

However, the SEM revealed that certain traits that were predictive of emergence either have a negative or mixed impact on criteria of leader effectiveness. This was mainly seen for Curiosity, a trait marked by high openness, creativity, imagination, and cognitive complexity. Laursen \& Salter's (2014) research has suggested the relationship is curvilinear, with excessive levels of curiosity having a negative impact on performance. Additionally, research has also indicated that having higher scores on Curiosity-related facets (e.g. fantasy on Openness to Experience) is associated with greater procrastination (Schouwenburg \& Lay, 1995) and lower ability to meet deadlines (Kim et al., 2017), implying that the highly curious are less able to complete tasks due to becoming distracted. This is partially reflected in the current study, as leaders with higher Curiosity were found to have achieved a lower proportion of performance targets. However, leader Curiosity was positively associated with increased organisational sales growth. Previous research has found a positive relationship between employee creativity and sales, but only in instances of high-quality leader-member exchange (Martinaityte \& Sacramento, 2013). The relationship between leader $\mathrm{Cu}$ riosity and sales growth could, therefore, be the result of leaders fostering higher quality relationships with their employees as a result of sharing a similar passion for novelty and creativity. Additionally, work-related curiosity has been linked to worker innovation (Celik et al., 2016), which could indicate that leaders with higher levels of curiosity are generating innovative products or solutions that compete better in market. However, the absence of a relationship between leader curiosity and organisational innovation indicates that this link is not a necessary requisite to drive sales growth. Future research should focus on exploring this relationship further, examining potential interaction variables that explain the when leader curiosity and innovation impacts sales growth, as well as where employee-leader homophily in curiosity or creativity predicts better leader-member exchange relationships and consequential sales performance.

Interestingly Conscientiousness and Competitiveness did not have a significant impact on leadership effectiveness in the SEM. Conscientiousness has previously been shown to be one of the single biggest predictors of leadership success (Teodorescu et al., 2017). However recent research has shown that the positive impact of conscientiousness could be negated by other leader attributes, which moderate the conscientiousness-performance relationship by altering the behavioural manifestation of conscientiousness (Harris et al., 2019). Additionally, Judge and Bono (2000) found that conscientiousness was not significantly predictive of transformational leadership, particularly after controlling for other Big 5 traits, arguing that highly conscientious leaders might hinder their success by failing to delegate and engage in overly close supervision. As high levels of Competitiveness are associated with a desire for recognition, power, and to win against others, it could hinder leader effectiveness by leaders prioritising the self over the performance of the team or organisation. 
This study highlights the differing roles that personality traits play in leader emergence and effectiveness. There appear to be certain traits that are universally beneficially for leadership, namely Adjustment, Risk Approach, and Ambiguity Acceptance. Combining theories of leadership emergence (e.g. Furnham et al., 2013) and models of leadership (e.g. Behrendt et al., 2017), these traits appear to reflect an individual's ability to demonstrate task-orientation (e.g. dependability, work ethic) and the ability to build and utilise relationships within the workplace (e.g. ability to remain calm under pressure and guide others). However, certain traits that are associated with emergence were not consistently associated with effectiveness. Arguments could be that there is a reduced range of these traits, meaning there is not a large enough variance in levels of a trait to be able to fully establish or distinguish the performance of leaders. However, the range of leader trait scores (as seen in Table 5) did not appear to be apparently different from the range of scores seen in the general population. For Another reason for this could be that these traits only show a positive impact on effectiveness in the presence of other leadership attributes. There is a need for future theories and studies of leadership to better understand why traits that promote someone to leadership do not manifest into increased performance.

\section{Leadership, Competencies and Performance}

The second aim of this study aimed to address calls by scholars to extent leader trait research by exploring the interactive role of leader attributes on organisational outcomes. Interestingly though, leadership competencies only significantly predicted one organisational outcome: leaders that rated their strengths as Strategic Vision and Effective Communicator were seen to have higher rates of internal promotions, prioritising internal candidates rather than 'parachuting' someone external in. Leader personality, however, was found to influence which competencies leaders perceived themselves to have. For instance, leaders with high Curiosity viewed innovation as one of their main leadership strengths. This result makes sense, as there are overlapping characteristics of innovation and Curiosity (e.g. creativity, imagination). Additionally, previous research found that innovative performance in organisations was explaining by leadership styles defined by seeking out novelty and experimenting with new ideas (Laursen \& Salter, 2006). Leader Curiosity was also predictive of perceiving their leadership being characterised as empowering for others. Previous research has linked leader empowerment with increased employee creativity (Zhang \& Bartol, 2010a, 2010b), moderated by leaders encouraging creativity. The results of this study indicate that highly curious leaders encourage and empower their employees to take equally novel and innovative approaches to their work.

Leader Competitiveness was negatively predictive of whether they viewed being Collaborative as a leadership strength. The result is somewhat circular, as competing and co-operating have been argued to be mutually exclusive concepts or exist at opposite ends of the same continuum. Additionally, leaders who have a higher need for power (a trait associated with higher Competitiveness) are less likely to engage in co-operative behaviours (e.g. seeking out advice from others; 
Tost et al., 2012).

The results of this study provide further support for the important role that Adjustment has in leadership success. Additionally, leader Adjustment was negatively related to using Proactive Conflict Manager. Previous research has suggested that neuroticism (low Adjustment) is positively related to using an avoidant (refraining from communicating with other) or obliging (neglecting own concern to satisfy needs of other) style of conflict management (Antonioni, 1998). Reviews of the literature also revealed that neuroticism is predictive of greater non-confrontational and compromising conflict strategies but causing people to be less likely to engage in confrontation conflict resolution (Moberg, 2001). The results of this study seem to suggest contradicting results to the previous literature, with highly emotionally adjusted leaders being less likely to proactively engage in conflict management. The results indicate that these leaders could have a higher threshold for what they consider to be conflict or interpersonal issues that need 'resolving'. Alternatively, this study analysed leadership competencies via a comparative, rank-order methodology. It could be that highly adjusted leaders simply choose alternative strategies (e.g. Effective Communicator) before Proactive Conflict Management, which would have caused these contradictory results.

However, no other competencies were able to explain significant variance in organisational outcomes after the role of leader personality. Scholars have called for research to investigate how additional leadership attributes explain variance in organisational outcomes (Zaccaro et al., 2018). However, this study found that leadership attributes either did not directly predict a large range of organisational outcomes or when they were predictive, no interaction effect was possible to examine because leader personality did not impact those outcomes (e.g. examining a potential mediating role of leader competencies). These results demonstrate that, whilst the leader personality-performance relationship has been criticised previously for potentially being too narrow in its research scope, when leader traits and attributes are assessed simultaneously, personality traits are the primary predictors of organisational outcomes. This is potentially because leader traits and competencies are not distinct enough for competencies to uniquely explain variance in outcomes. If leader attributes are to play a direct or dynamic role in predicting organisational outcomes alongside leader traits, further research is needed to identify which attributes are distinct enough from traits that they are able to account for additional or unique variance.

Organisations, academics, and practitioners have a need to successfully identify their next generation of leaders; the "high potential" individuals that will go on to lead (MacRae \& Furnham, 2014). To successfully identify "what good likes like" for a leader, it is important to understand how leader personality contributes to and influences organisational success. This present study offers insight into how specific personality traits differentiate those leaders that are driving performance in their organisation from those that are potentially hindering it. For academics in this field, it offers evidence for the direct and specific role that leader personality plays in explaining differences in organisational performance 
metrics. For practitioners, it provides a framework for identifying the personality traits that identify potential by examining what is currently driving success.

This study is not without limitations. The first limitation is the cross-section nature of this design. Leadership personality was collected alongside organisational performance data, potentially introducing error in establishing causality (Wright et al., 2003; Meier \& Spector, 2013). However, the theoretical nature of the stability of personality and the volatility of outcome measures assessed provide reassurance that the assumed causality is accurate. However, future research should look to run longitudinal studies on leader personalities in predicting organisational performance one, three, and five years after personality assessment to understand the short, medium, and long-term impact of leader personality on organisational performance. Additionally, the reliance on self-report has been criticised by academics for potentially increasing common method variance (CMV) or monomethod bias, where statistically significant relationships are attributable to the common methodology rather than actual relationships between phenomenon (e.g. Podsakoff et al., 2003). However, this study examined the potential impact of CMV, finding that the chance was low. Additionally, scholars have criticism CMV for being a potential oversimplification or exaggeration (Spector, 2006). For instance, if CMV or monomethod bias was a holistic explanation of potential bias, it doesn't explain why studies that with large samples (i.e. $n>1500$ ) that utilise only self-report measures do not find that all self-reported variables significantly correlate (e.g. see Boswell et al. 2004 for a study with 1600 participants on turnover intention with $40 \%$ of correlations being non-significant). Instead, researchers have argued that CMV does not have a symmetric impact on research, but instead the extent to which it causes bias varies depending on inherent bias within measurement styles themselves (e.g. social desirability; Spector, 2006). However, if researchers want to further the leadership literature and understand the personality-performance relationship, future studies should look to replicate these findings by designing studies that are multi-method, for instance by collecting observational or behavioural data for leader attributes, such as peer-, manager-, or team-reports of behaviour. Additionally, a key limitation of this study is multiple testing (i.e. stepwise regressions). Whilst forms of stepwise procedures in psychological analysis has been criticised for increasing the chance of Type I error (e.g. Henderson \& Denison, 1989), researchers have argued that analyses have a lower chance of inflating Type I error when studies have: 1) near zero sum of squares explained across steps, 2) small number of predictor variables, and/or 3) large sample size (Thompson, 1995). Additionally, the use of stepwise procedures has been argued to be beneficial in exploratory, predictive research (Menard, 1995) as well as have the implication of suppressing the overall explanatory power of outcome variables due to the exclusion of suppressor variables. Additionally, as a function of this analysis methodology the results are exploratory. Whilst this was the aim of the study, and for the criticisms mentioned above, there is a need for future research to confirm these findings with additional research. Future research 
looking to confirm these results should be longitudinal in nature, with the three sets of variables being measured in temporal sequence to additionally overcome issues of cross-sectionality. Additionally, due to limitations of multiple testing, the confirmatory study should look to test an explicitly stated, restricted model.

\section{Conclusion and Practical Implications}

This study had two aims: firstly, are the traits that predict leadership emergence the same that predict leadership effectiveness? The exploratory results indicated that, whilst there are some traits that appear to be jointly beneficial, the relationship is not as straightforward as previously thought. Whilst all six HPTI traits were associated with leader emergence, only three (Adjustment, Risk Approach, and Ambiguity Acceptance) were shown to have a consistent positive impact on performance. Curiosity was found to have a negative impact on certain performance outcomes, indicating a potential "too much of a good thing" effect, where too high levels have a detrimental impact. Additionally, Conscientiousness and Competitiveness, whilst predictive of emergence, were not found to be significant predictors of leadership effectiveness. Secondly, this study found that personality is still a strong predictor of organisational outcomes after including and controlling for other leadership attributes (namely leadership competencies). The combination of these two aims demonstrates that models of leadership need to introduce more nuance into the specific dynamics and role that personality plays, where emergence and effectiveness are distinct processes requiring different traits.

There are some important implications of this study. First, that certain personality traits are good predictors of leadership success and hence it would do well for those interested in assessment and selection to consider them. Second, that some characteristics which assist an individual in emerging as a possible leader do not necessarily predict that they will succeed in the leadership role. Third, that two traits, namely Risk Approach and Ambiguity Acceptance, which are currently not assessed by the "Big Five" framework are important predictors of leadership success and therefore merit being measured in any leadership selection exercise.

\section{Conflicts of Interest}

The authors declare no conflicts of interest regarding the publication of this paper.

\section{References}

Antonioni, D. (1998). Relationship between the Big Five Personality Factors and Conflict Management Styles. International Journal of Conflict Management, 9, 336-355. https://doi.org/10.1108/eb022814

Bakker, A. B., \& Demerouti, E. (2014). Job Demands-Resources Theory. In P. Y. Chen, \& C. L. Cooper (Eds.), Work and Wellbeing: A Complete Reference Guide (pp. 1-28). Hoboken, NJ: John Wiley \& Sons. https://doi.org/10.1002/9781118539415.wbwell019 
Bargeron, L. L., Lehn, K. M., \& Zutter, C. J. (2010). Sarbanes-Oxley and Corporate Risk-Taking. Journal of Accounting and Economics, 49, 34-52. https://doi.org/10.1016/j.jacceco.2009.05.001

Barrett, G. V., \& Depinet, R. L. (1991). A Reconsideration of Testing for Competence Rather than for Intelligence. American Psychologist, 46, 1012-1025. https://doi.org/10.1037/0003-066X.46.10.1012

Barrick, M. R., Mount, M. K., \& Judge, T. A. (2001). Personality and Performance at the Beginning of the New Millennium: What Do We Know and Where Do We Go Next? International Journal of Selection and Assessment, 9, 9-30. https://doi.org/10.1111/1468-2389.00160

Bartram, D. (2005). The Great Eight Competencies: A Criterion-Centric Approach to Validation. Journal of Applied Psychology, 90, 1185-1203. https://doi.org/10.1037/0021-9010.90.6.1185

Behrendt, P., Matz, S., \& Göritz, A. S. (2017). An Integrative Model of Leadership Behavior. The Leadership Quarterly, 28, 229-244. https://doi.org/10.1016/j.leaqua.2016.08.002

Bono, J. E., \& Judge, T. A. (2004). Personality and Transformational and Transactional Leadership: A Meta-Analysis. Journal of Applied Psychology, 89, 901-910. https://doi.org/10.1037/0021-9010.89.5.901

Boswell, W. R., Boudreau, J. W., \& Dunford, B. B. (2004). The Outcomes and Correlates of Job Search Objectives: Searching to Leave or Searching for Leverage? Journal of Applied Psychology, 89, 1083-1091. https://doi.org/10.1037/0021-9010.89.6.1083

Canadian Labor Statistic (2017). Labor Force Characteristics by Occupation, Annual (x1000). Ottawa, ON: StatCan. https://www150.statcan.gc.ca/t1/tbl1/en/tv.action?pid=1410029701

Celik, P., Storme, M., Davila, A., \& Myszkowski, N. (2016). Work-Related Curiosity Positively Predicts Worker Innovation. Journal of Management Development, 35, 1184-1194. https://doi.org/10.1108/JMD-01-2016-0013

Colbert, A. E., Barrick, M. R., \& Bradley, B. H. (2014). Personality and Leadership Composition in Top Management Teams: Implications for Organizational Effectiveness. Personnel Psychology, 67, 351-387. https://doi.org/10.1111/peps.12036

Dixon, D. P., Weeks, M., Boland Jr., R., \& Perelli, S. (2017). Making Sense When It Matters Most: An Exploratory Study of Leadership in Extremis. Journal of Leadership \& Organizational Studies, 24, 294-317. https://doi.org/10.1177/1548051816679356

Ensari, N., Riggio, R. E., Christian, J., \& Carslaw, G. (2011). Who Emerges as a Leader? Meta-Analyses of Individual Differences as Predictors of Leadership Emergence. Personality and Individual Differences, 51, 532-536.

https://doi.org/10.1016/j.paid.2011.05.017

Furnham, A., Hyde, G., \& Trickey, G. (2013). The Values of Work Success. Personality and Individual Differences, 55, 485-489. https://doi.org/10.1016/j.paid.2013.04.016

Goldberg, L. R. (1992). The Development of Markers for the Big-Five Factor Structure. Psychological Assessment, 4, 26-42. https://doi.org/10.1037/1040-3590.4.1.26

Grijalva, E., Harms, P. D., Newman, D. A., Gaddis, B. H., \& Fraley, R. C. (2015). Narcissism and Leadership: A Meta-Analytic Review of Linear and Nonlinear Relationships. Personnel Psychology, 68, 1-47. https://doi.org/10.1111/peps.12072

Harris, T. B., Cardador, M. T., Cole, M. S., Mistry, S., \& Kirkman, B. L. (2019). Are Followers Satisfied with Conscientious Leaders? The Moderating Influence of Leader Role Authenticity. Journal of Organizational Behavior, 40, 456-471.

https://doi.org/10.1002/job.2342 
Henderson, D. A., \& Denison, D. R. (1989). Stepwise Regression in Social and Psychological Research. Psychological Reports, 64, 251-257. https://doi.org/10.2466/pr0.1989.64.1.251

Hogan, R., \& Hogan, J. (2001). Assessing Leadership: A View from the Dark Side. International Journal of Selection and Assessment, 9, 40-51. https://doi.org/10.1111/1468-2389.00162

Hogan, R., \& Judge, T. (2013). Personality and Leadership. In M. G. Rumsey (Ed.), The Oxford Handbook of Leadership (pp. 37-46). Oxford: Oxford University Press. https://doi.org/10.1093/oxfordhb/9780195398793.013.0003

Hogan, R., \& Kaiser, R. B. (2005). What We Know about Leadership. Review of General Psychology, 9, 169-180. https://doi.org/10.1037/1089-2680.9.2.169

Hogan, R., Curphy, G. J., \& Hogan, J. (1994). What We Know about Leadership: Effectiveness and Personality. American Psychologist, 49, 493-504.

https://doi.org/10.1037/0003-066X.49.6.493

Joyce, W. F., Nohria, N., \& Roberson, B. (2003). What Really Works: The 4-2 Formula for Sustained Business Success. New York: Harper Business.

Judge, T. A., \& Bono, J. E. (2000). Five-Factor Model of Personality and Transformational Leadership. Journal of Applied Psychology, 85, 751-765. https://doi.org/10.1037/0021-9010.85.5.751

Judge, T. A., Bono, J. E., Ilies, R., \& Gerhardt, M. W. (2002). Personality and Leadership: A Qualitative and Quantitative Review. Journal of Applied Psychology, 87, 765-780. https://doi.org/10.1037/0021-9010.87.4.765

Judge, T. A., Piccolo, R. F., \& Kosalka, T. (2009). The Bright and Dark Sides of Leader Traits: A Review and Theoretical Extension of the Leader Trait Paradigm. The Leadership Quarterly, 20, 855-875. https://doi.org/10.1016/j.leaqua.2009.09.004

Kim, S., Fernandez, S., \& Terrier, L. (2017). Procrastination, Personality Traits, and Academic Performance: When Active and Passive Procrastination Tell a Different Story. Personality and Individual Differences, 108, 154-157. https://doi.org/10.1016/j.paid.2016.12.021

Laursen, K., \& Salter, A. (2006). Open for Innovation: The Role of Openness in Explaining Innovation Performance among UK Manufacturing Firms. Strategic Management Journal, 27, 131-150. https://doi.org/10.1002/smj.507

Laursen, K., \& Salter, A. J. (2014). The Paradox of Openness: Appropriability, External Search and Collaboration. Research Policy, 43, 867-878.

https://doi.org/10.1016/j.respol.2013.10.004

Li, K., Griffin, D., Yue, H., \& Zhao, L. (2013). How Does Culture Influence Corporate Risk-Taking? Journal of Corporate Finance, 23, 1-22. https://doi.org/10.1016/j.jcorpfin.2013.07.008

MacRae, I. (2012). Success, Potential and Validating a Measure of High Flying Personality Traits in Organisations. Unpublished Master's Dissertation, London, UK: University College London.

MacRae, I., \& Furnham, A. (2014). High Potential: How to Spot, Manage and Develop Talented People at Work. London: Bloomsbury Publishing.

Maltz, A. C., Shenhar, A. J., \& Reilly, R. R. (2003). Beyond the Balanced Scorecard: Refining the Search for Organizational Success Measures. Long Range Planning, 36, 187-204. https://doi.org/10.1016/S0024-6301(02)00165-6

Markus, L., Thomas, H. C., \& Allpress, K. (2005). Confounded by Competencies? An Evaluation of the Evolution and Use of Competency Models. New Zealand Journal of Psychology, 34, 117-126. 
Martinaityte, I., \& Sacramento, C. A. (2013). When Creativity Enhances Sales Effectiveness: The Moderating Role of Leader-Member Exchange. Journal of Organizational Behavior, 34, 974-995. https://doi.org/10.1002/job.1835

Meier, L. L., \& Spector, P. E. (2013). Reciprocal Effects of Work Stressors and Counterproductive Work Behavior: A Five-Wave Longitudinal Study. Journal of Applied Psychology, 98, 529-540. https://doi.org/10.1037/a0031732

Menard, S. (1995). Applied Logistic Regression Analysis (Sage University Paper Series on Quantitative Applications in the Social Sciences, Series No. 07-106). Thousand Oaks, CA: Sage.

Moberg, P. J. (2001). Linking Conflict Strategy to the Five-Factor Model: Theoretical and Empirical Foundations. International Journal of Conflict Management, 12, 47-68. https://doi.org/10.1108/eb022849

Ng, K. Y., Ang, S., \& Chan, K. Y. (2008). Personality and Leader Effectiveness: A Moderated Mediation Model of Leadership Self-Efficacy, Job Demands, and Job Autonomy. Journal of Applied Psychology, 93, 733-743. https://doi.org/10.1037/0021-9010.93.4.733

Podsakoff, P. M., MacKenzie, S. B., Lee, J. Y., \& Podsakoff, N. P. (2003). Common Method Biases in Behavioral Research: A Critical Review of the Literature and Recommended Remedies. Journal of Applied Psychology, 88, 879-903.

https://doi.org/10.1037/0021-9010.88.5.879

Pollanen, R., Abdel-Maksoud, A., Elbanna, S., \& Mahama, H. (2017). Relationships between Strategic Performance Measures, Strategic Decision-Making, and Organizational Performance: Empirical Evidence from Canadian Public Organizations. Public Management Review, 19, 725-746. https://doi.org/10.1080/14719037.2016.1203013

Schouwenburg, H. C., \& Lay, C. H. (1995). Trait Procrastination and the Big-Five Factors of Personality. Personality and Individual Differences, 18, 481-490. https://doi.org/10.1016/0191-8869(94)00176-S

Silzer, R., \& Church, A. H. (2009a). The Pearls and Perils of Identifying Potential. Industrial and Organizational Psychology, 2, 377-412. https://doi.org/10.1111/j.1754-9434.2009.01163.x

Silzer, R., \& Church, A. H. (2009b). The Potential for Potential. Industrial and Organizational Psychology, 2, 446-452. https://doi.org/10.1111/j.1754-9434.2009.01172.x

Slawinski, N., Pinkse, J., Busch, T., \& Banerjee, S. B. (2017). The Role of Short-Termism and Uncertainty Avoidance in Organizational Inaction on Climate Change: A Multi-Level Framework. Business \& Society, 56, 253-282. https://doi.org/10.1177/0007650315576136

Spector, P. E. (2006). Method Variance in Organizational Research: Truth or Urban Legend? Organizational Research Methods, 9, 221-232.

https://doi.org/10.1177/1094428105284955

Teodorescu, A., Furnham, A., \& MacRae, I. (2017). Trait Correlates of Success at Work. International Journal of Selection and Assessment, 25, 36-42. https://doi.org/10.1111/ijsa.12158

Thompson, B. (1995). Stepwise Regression and Stepwise Discriminant Analysis Need Not Apply Here: A Guidelines Editorial. Educational and Psychological Measurement, 55, 525-534. https://doi.org/10.1177/0013164495055004001

Tost, L. P., Gino, F., \& Larrick, R. P. (2012). Power, Competitiveness, and Advice Taking: Why the Powerful Don't Listen. Organizational Behavior and Human Decision Processes, 117, 53-65. https://doi.org/10.1016/j.obhdp.2011.10.001

Tuncdogan, A., Acar, O. A., \& Stam, D. (2017). Individual Differences as Antecedents of Leader Behavior: Towards an Understanding of Multi-Level Outcomes. The Leadership Quarterly, 28, 40-64. https://doi.org/10.1016/j.leaqua.2016.10.011 
Waldman, D. A., \& Yammarino, F. J. (1999). CEO Charismatic Leadership: Levels-of-Management and Levels-of-Analysis Effects. Academy of Management Review, 24, 266-285. https://doi.org/10.5465/amr.1999.1893936

Wright, P. M., Gardner, T. M., \& Moynihan, L. M. (2003). The Impact of HR Practices on the Performance of Business Units. Human Resource Management Journal, 13, 21-37. https://doi.org/10.1111/j.1748-8583.2003.tb00096.x

Zaccaro, S. J., Green, J. P., Dubrow, S., \& Kolze, M. (2018). Leader Individual Differences, Situational Parameters, and Leadership Outcomes: A Comprehensive Review and Integration. The Leadership Quarterly, 29, 2-43.

https://doi.org/10.1016/j.leaqua.2017.10.003

Zhang, X., \& Bartol, K. M. (2010a). Linking Empowering Leadership and Employee Creativity: The Influence of Psychological Empowerment, Intrinsic Motivation, and Creative Process Engagement. Academy of Management Journal, 53, 107-128.

https://doi.org/10.5465/amj.2010.48037118

Zhang, X., \& Bartol, K. M. (2010b). The Influence of Creative Process Engagement on Employee Creative Performance and Overall Job Performance: A Curvilinear Assessment. Journal of Applied Psychology, 95, 862-874. https://doi.org/10.1037/a0020173 